OLIVEIRA, Iranilson Buriti de. Artes de curar e modos de viver na geografia do cangaço. História, Ciências, Saúde Manguinhos, Rio de Janeiro, v.18, n.3, jul.-set. 2011, p.745-755.

\title{
Resumo
}

\section{Artes de curar e modos de viver na geografia do cangaço}

\section{The healing arts and ways of life in the geographical realm of the cangaço}

Iranilson Buriti de Oliveira

Professor da Universidade Federal de Campina Grande; bolsista de Produtividade do CNPq.

Condomínio Nações Residence Privê. BR 104, Km 119

58117-000 - Lagoa Seca - PB - Brasil

iburiti@yahoo.com.br

Recebido para publicação em setembro de 2009

Aprovado para publicação em junho de 2011.

Discute as práticas de cura,

especificamente remédios e ervas,

utilizadas pelos cangaceiros do

Nordeste brasileiro, na virada do século

XIX para o XX. Na análise, recorre-se

aos pressupostos teórico-metodológicos

da nova história cultural e dos estudos culturais, em diálogo com Michel de

Certeau e Stuart Hall, entre outros.

Problematiza o modo como os

cangaceiros recorriam, em seu

cotidiano, a mezinhas, chás, orações a

santos católicos, além de produtos da

farmacopeia regional, para alcançar a

cura e o bem-estar do corpo. Observa

como os espaços de cura são recriados e

os saberes populares, subjetivados na geografia do cangaço.

Palavras-chave: práticas de cura; cangaço; Nordeste; Brasil.

\section{Abstract}

This analysis of the remedies and herbs used in healing practices by the cangaceiros of Northeast Brazil in the late nineteenth/early twentieth centuries applies the theoretical and methodological assumptions of new cultural history and cultural studies in a dialogue that includes Michel de Certeau, Stuart Hall, and others. It problematizes how the cangaceiros relied regularly on folk remedies like mezinhas, teas, and prayers to Catholic saints, as well as regional medicines, in healing the body and re-establishing good health. Within the geographical realm of the cangaço, healing spaces were re-created and folk knowledge was subjectivized.

Keywords: healing practices; cangaço; Northeast; Brazil. 
$\mathrm{N}^{\circ}$ ordeste do Brasil, fins do século XIX e início do XX. ${ }^{1}$ Uma estética do medo começa a ganhar visibilidade e expressividade no cenário da seca. Emerge como problema histórico a figura do cangaceiro, um corpo que fala da morte, mas que também elabora uma retórica para a vida baseada na fuga, na luta, nos esconderijos, na conquista de cidades, nos saques, nos rituais de cura. Uma escrita é elaborada na região, cujos vocábulos pautam-se em outros emblemas que não a passividade e a subserviência ao Centro-sul; uma narrativa que desconstrói a estética da passividade do pobre aos (co)mandos do rico. Desponta um corpo de homens e mulheres que fogem do cenário da família e elaboram outras dobras para si, subjetivam outros territórios, outras curvaturas. ${ }^{2}$ Os cangaceiros são sujeitos que inventaram outras cartografias, que desenharam a ferro e fogo novas paisagens de vida. Escreveram um dicionário em que estão significadas outras palavras, escritos outros nomes, elaborados outros desejos - desejos incompreendidos, perseguidos, estereotipados, mas ainda assim desejos, pulsações, micropolíticas.

Neste artigo, abordo a cartografia do cangaço a partir de outro lugar. Não aquele do marxista, que coloca o sujeito cangaceiro como herói ou bandido, mas sim o de um historiador da terceira margem, "fruto das atividades de purificação, de racionalização, de construção humana e social de objetos e de sujeitos como entidades separadas [que] vêm se encontrar, se misturar no fluxo, no turbilhonar das ações e práticas humanas" (Albuquerque Júnior, 2007, p.26). Não falo do cangaceiro nem do cangaceirismo em si, como um ritual de violência, mas me aproprio desse território de corpos mutilados, marcados por peixeiras, penetrados por espinhos e balas, tatuados por rasgões de juremas, macambiras, xiquexiques e demais cactos, mas também território de sonhos, desejos, projetos de vida, cura, amores. Este é o cenário de falas e gestos que encanta o historiador, o qual se apossa dessa geografia para falar de outra: aquela da cura, das benzeduras, da sabedoria popular.

Minha proposta, portanto, é um recurvar-se que cria outras dobras para o cangaço. Tomo posse de uma territorialidade para desenhar outra. Faço uma viagem em meio aos mandacarus para analisar e problematizar de que modo foram elaborados os discursos e ritos de cura pelos participantes do cangaceirismo, mestres e artesãos de táticas de sobrevivência. Pretendo situar o corpo do cangaçeiro como depositário de signos sociais, compreendendo-o modelado ou 'construído' pela cultura em que está inserido. ${ }^{3}$ Pretendo analisar a saúde e as doenças como objetos da história, pois que as últimas, até pouco tempo, constituíam cenários de estudos de médicos, químicos, biólogos, mas também emergem como campo de análise do historiador, pois "a doença pertence à história superficial dos progressos científicos e tecnológicos como também a história profunda dos saberes e práticas ligadas às estruturas sociais, às instituições ..." (Le Goff, 1985, p.7).

Para elaborar este artigo, fruto de pesquisa levada a efeito na Universidade Federal de Campina Grande, Paraíba, fui em busca de artigos, livros e notícias que relacionassem o cangaço às práticas de cura. Uma busca difícil, já que se trata de temática pouco abordada por historiadores e demais pesquisadores da área de história da saúde e da doença. Assim, as obras aqui mencionadas (a maioria escrita por sociólogos e médicos) são documentos 'garimpados' e transformados em 'monumentos', e por meio deles pude intuir e elaborar as relações, até então pouco analisadas, entre a geografia do cangaço e os espaços de cura. 
Recortada temática e metodologicamente esta pesquisa, interrogo: que modos e formas de cura estavam presentes nesse cenário? Que marcas da sabedoria popular, das mezinhas e benzeduras, dos conhecimentos não legitimados cientificamente faziam parte desse lugar praticado, chamado cotidiano - cotidiano este que, longe de configurar uma rotina, significa inventividade, mudanças, rupturas, possibilidade de novos modos de ser e estar, de ter e viver, de criação de redes socioculturais? ${ }^{4}$ Uma face transgressora ao burlar a repressão disciplinadora das tramas sociais; espaços que se fazem a partir das práticas e de seus relatos. Estudar esse cotidiano possibilita-nos esmiuçar as práticas de sobrevivência no cangaço como formas de vida e não de sobrevida, como um lugar produzido, um ambiente ressignificado, um corpo regional historicamente tecido, ligado a operações e definido por funcionamentos. O que representa a benzedura, nessa geografia do 'crime' e da fuga? Representa uma fonte de resistência, subterfúgios possíveis de um cotidiano improvisado, táticas que são reinventadas. Representa, ainda, o repensar das tradições coloniais, o diálogo entre magia e medicina, entre religião e feitiçaria, entre Esculápio, Jesus Cristo e outros deuses.

Certo olhar historiográfico construiu um lugar para o cangaço e para o cangaceiro: o lugar de mito, de herói ou de bandido, de tradição festejada ou repudiada. Fujo desse lugar porque não me identifico com ele, porque faz parte da escrita de uma história atrelada e apegada a valores históricos (mitos, heróis, lugares) que tanto a história cultural quanto os estudos culturais criticam e põem em suspeição. Assim como os cangaceiros fugiam dos perigos à vista, fujo também desse estilo de escrita que, em uma folha de história regional, iguala diferenças, apaga vozes, enclausura experiências e poda saberes que os sujeitos utilizam para construir e definir suas identidades, compreendendo e recriando os mundos em que vivem. Fujo de uma história dicotômica (heróica ou bandida) e mergulho nas subjetividades múltiplas, não homogêneas, em novas curvaturas para esse campo de estudo. A partir de novas abordagens historiográficas, procuro quebrar essa tradição e inventar outros corpos, questionando a ideia do cangaceirismo como um movimento homogêneo, tão somente marcado pela violência.

Abordar a geografia de cura no cangaço significa mergulhar em um cenário ainda pouco visitado historicamente, pouco explorado pelos pesquisadores. Trata-se de adentrar um território de muitos espinhos acadêmicos, pois as veredas, além de estreitas, são pontuadas por ciladas metodológicas, arames teóricos, farpas medonhas, assustadoras para o transeunte que tenta, se não conquistar, ao menos interpretar os sujeitos que praticam esse território. Território mitificado por uns, odiado por outros, que repugna a muitos. Enveredar nessas trilhas possibilita uma leitura de um objeto da história quase silenciado, esquecido, de mulheres e homens que aceitaram o desafio de construir outros mapas das práticas curativas. São relatos de uma travessia efêmera, dos tempos múltiplos de antes e de depois da cura, de experiências diversas; de táticas e estratégias de sobrevivência de um corpo que anda, que mapeia, que marca o chão do Nordeste com outros ritos de saber.

Estudar os caminhos de cura no cangaço significa procurar as práticas dispersas em múltiplas estratégias de sobrevivência, porém difíceis de serem apreendidas sob a aparência cada vez mais homogênea de massificação, que transforma o cangaço num corpo linear, atravessado apenas pela violência, elaborando a identidade do cangaceiro a partir do 
binarismo (má ou boa, isto ou aquilo), que percebe o sujeito como deus ou como demônio. Não é esse o meu objetivo, pois como afirma o historiador Albuquerque Júnior (2007, p.35), o pesquisador pode mover-se na terceira margem, pois a "consciência irônica do meu tempo me faz praticar meu ofício como um lugar de desconstrução do rosto sério e sisudo das verdades definitivas e estabelecidas".

Classificar não faz parte deste roteiro. Mediante uma arqueologia da percepção (Machado, 1978), me importa investigar a sabedoria popular, o saber não legitimado pela medicina, o conhecimento que faz do cangaceiro uma vida possuidora de outras práticas de viver, de fazeres e de saberes inventados e reinventados cotidianamente, uma história das resistências. Resistências que, como diz Michel de Certeau, surgem da capacidade que os sujeitos têm de nos mostrar o movimento potente da vida ordinária, da convicção de que nenhuma situação é, a princípio, fixa e irresistível. Subjetividades que emergem dos movimentos de microrresistências que ganham fôlego no cotidiano.

De que táticas esses homens ordinários lançavam mão, em seu cotidiano, para curar suas feridas, amenizar suas dores, diagnosticar seus maus humores? ${ }^{5}$ Que sujeitos são esses que, marcados para morrer, em muitos casos, acabavam sobrevivendo; que, longe dos postos de profilaxia rural e das práticas médico-higienistas, construíam outros territórios de cura e higienização? Interessa, neste artigo, pensar outras formas de viver no cangaço, de burlar códigos médicos, de driblar situações de desespero diante da dor e perante a morte.

Pensar as práticas de cura no cangaço é uma maneira de viabilizar aberturas para outros campos de estudo desse evento que marcou o Nordeste, percorrendo ricos acontecimentos que podem ser construídos e multiplicados pela pesquisa e pela escrita. Dessa forma, pensar a relação entre cangaço e práticas de cura constitui um mergulho nos saberes populares e em outros modos de existir, resistir e inventar a vida. Trata-se de analisar a cultura como uma forma de representar o lugar de cada um no mundo, sua relação com as crenças e valores. Nesse ambiente de ausência do saber médico-científico, possuir conhecimento médicopopular torna-se um instrumento de diferenciação, um corpus de saber que estabelece hierarquias, uma dobra para pensar a existência.

É em Michel de Certeau (1999) que iremos buscar a compreensão das formas de criar alternativas de cura, tentando evidenciar as 'artes de fazer' daqueles para quem foi elaborado o lugar da morte. O cotidiano surge como espaço privilegiado de produção de táticas de vida, itinerários de cura, invenções de garrafadas, chás, infusões, lambedores. Invenção de um lugar para sarar feridas expostas, cicatrizar aberturas provocadas por balas, a elaboração de um cotidiano no qual o sujeito utiliza táticas de enfrentamento da morte e da dor e se apodera de seus modos de ser para desafiar a sepultura. Táticas que se configuram fontes de resistência à geografia da morte, intercalando-se como subterfúgios possíveis de um cotidiano improvisado, sempre em processo de reinvenção e recriação. Táticas de viver que podem ser compreendidas como movimentos do cotidiano de sujeitos ordinários, elaborados numa combinação de maneiras de pensar investidas numa maneira de agir. Essa combinação pensar/fazer/agir promove uma fuga para seus impasses, dando ao articulador de tal movimento uma característica tática, transformando o pensamento em arte, a arte em vida, a vida em corpo de rebeldias. Táticas que, somadas à arte e à vida, 
ganham nomes de remédios: chá de formiga, gargarejo com sal, banha de capivara, chá de osso de jumento, carne de cascavel, banha de traíra.

Diz Certeau (1999, p.47): “A tática depende do tempo, vigiando para 'captar no voo' a possibilidade de ganho. $\mathrm{O}$ que ela ganha não o guarda. Tem que constantemente jogar com os acontecimentos para os transformar em 'ocasiões'". Se as táticas dependem do tempo e das possibilidades de alcançá-las através dos voos, os cangaceiros do Nordeste voaram na sabedoria popular, revisitaram as lembranças de outrora, lançaram mão da memória popular, reinventaram a gramática e o vocabulário da farmacopeia nordestina. O que necessitavam nem sempre estava nas prateleiras das boticas. Transformaram o corpo fármaco popular em uma linguagem de vida, um dicionário de curas, um vocabulário de receitas, um alfabeto de bulas. No meio do mato, em meio às pedras, no meio da areia, todos eram charlatães, curandeiros, mágicos, médicos de corpos e de alma.

Lampião, Corisco, Maria Bonita, Dadá, Jararaca. Quando invocados por outros sujeitos do bando, eles têm quase sempre uma receita, um diagnóstico, um clister para resolver as situações, conforme narrado por Aglaê Lima de Oliveira (1982), em Lampião, cangaço e Nordeste. Nessas horas, assumem a identidade ${ }^{6}$ de curadores, terapeutas, parteiros, parteiras, cirurgiões que lançam mão da peixeira, em vez do bisturi, para cortar, sangrar, coser, pontear, fazer suturas, vomitórios, mapear a carne triada e machucada, cartografar o corpo debilitado e espancado. Corpos que rasgam, corpos que curam, corpos que matam e dão a vida, como analisou a socióloga Maria Isaura Pereira de Queiroz (1991, cf. Lucena, Gouveia Júnior, 2001, p.4), mostrando que, na hora da dor, os cangaceiros também recorriam a magias e superstições, amuletos e rezas fortes, servindo-se algumas vezes de rezadeiras, beatos e fanáticos para ajudar no ato da cura. Sujeitos corporificados a narrar a valentia e construir sentidos que influenciam e organizam tanto nossas ações quanto a concepção que temos de nós mesmos, corpos do Nordeste. Sob tal 'lógica' identitária foi elaborada a noção de que todo nordestino é forte, valente e destemido, como dissertou Albuquerque Júnior (2004), na obra O nordestino e a invenção do falo. Ao construir esse sentido para o Nordeste, sentido com o qual podemos nos identificar, construímos também identidades, inventamos uma tradição ${ }^{7}$, elaboramos uma narrativa fundacional. Olhar para o cangaço parece ser, muitas vezes, reencontro com uma tradição nordestina, com um mito fundador da braveza da região, que desafiou 'macacos's, volantes, governadores e políticos. Uma narrativa que solapa as diferenças e estabelece estereótipos.

Lampião, Antonio Silvino, Corisco, Jararaca. Quem são eles? São homens que puxaram a peixeira e com a sua ponta escreveram, nas páginas da areia do Nordeste, uma narrativa fundacional, uma história alternativa ou contranarrativa para essa região. Inventaram um espaço possível, ocuparam um território de movimentação, elaboraram outras dobras da existência, outras vivências, algumas delas analisadas em livros e filmes. Mas a região, assim como a sua história, é uma relação da linguagem com o corpo social, com os limites impostos pelo corpo. A linguagem é um "terceiro termo que conecta e articula natureza e cultura" (Albuquerque Junior, 2007, p.34). Se há narrativa, há contranarrativa. Se há morte, há vida. Se há doença, talvez haja cura. Se há corpo, existe a linguagem que mata o silêncio, a escrita que renova palavras e gestos comuns. O espaço de cura e de convivência elaborado por esses sujeitos é tecido a partir de aproximações, distanciamentos, conflitos, 
intrigas, contendas, afrontamentos, sensos e dissensos. Sua história é rebento do encontro entre poder e linguagem, uma operação que articula um lugar social, uma disciplina do conhecimento e a elaboração de um texto espacial. Como diz Albuquerque Júnior (2008), as atividades humanas carregam em si uma dimensão espacial.

As fronteiras, as identidades espaciais, os territórios, os lugares passam a ser pensados como tendo sido definidos a partir de contendas, de conflitos, sendo frutos de relações que se estabeleceram entre diferentes agentes e agências em um dado momento histórico, sendo portanto, passíveis de dissolução, desconstrução, sempre que as relações sociais que os engendraram sejam modificadas, que os saberes que os puseram de pé sejam desmontados e que as relações de poder que os sustentaram sofram deslocamentos (p.71-72).

Para entender essa geografia de morte e vida é necessário visitar Stuart Hall (2005), para quem a identidade não é, em si mesma, uma fechadura. Há canais de identificações. O cangaceiro não possui uma fronteira identitária. Pode haver contradições em seu interior que precisam ser negociadas. Ele não é uno, homogêneo, territorializado apenas pelas armas, cartografado somente pela peixeira, pela espingarda, pelas práticas de matar. Esse sujeito que mata também cura, faz partos, mezinhas, rezas, bochechos (Oliveira, 1982, p.133-134). Lampião odeia, mas também ama. Faz do amor uma arma, uma droga que atinge o coração de Maria, a bonita, amor este documentado, entre outras obras, pela minissérie Lampião e Maria Bonita9 e pelos filmes Corisco e Dadá (1996) e O cangaceiro (1953). Entre matar, amar, curar, rezar existem vários Lampiões, inúmeras identidades de sujeito. Entre o amor silente de Lampião e a linguagem de seus gestos surge o verbo comunicado. E é o amor de Lampião que suscita aos cangaceiros um importante problema: com Maria Bonita, provavelmente a primeira mulher a fazer parte de um grupo de cangaceiros de que se tem notícia (Almeida, 2006, p.5), abre-se a possibilidade de que outras mulheres o acompanhem. Com isso, questões da menstruação, da gestação e do parto passam a se fazer presentes nessa cartografia: "A gravidez no cangaço era uma grande preocupação para os grupos. Além de serem redobrados os cuidados com a segurança do bando, eles procuravam lugares ermos, fora da rota de volantes, mas próximos a coiteiros de confiança e, eventualmente, de uma boa parteira" (Araújo, Fernandes, 2005, p.87).

Se a vida no cangaço já era espinhosa para os adultos, idealize o leitor o quanto não o seria para uma criança! A amamentação e o cuidado inicial dos rebentos 'cangaceiros' raramente eram realizados por suas genitoras naturais, porque, na maior parte das vezes, eles eram entregues aos cuidados de amigos de confiança dos bandoleiros: "Assim ocorreu com Expedita Ferreira, filha única de Lampião e Maria, que logo após o nascimento foi entregue pelo pai a um casal que já tinha onze filhos; durante os cinco anos e nove meses que viveu até o falecimento dos seu pais, só foi visitada três vezes" (Almeida, 2006, p.116).

Além disso, na geografia do cangaço, se o auxílio de parteiras era exceção, a presença do médico na hora do parto era uma completa raridade, e a falta de assistência e o óbito no parto (da mãe ou da criança) eram quase uma regra (Araújo, Fernandes, 2005, p.87-89). Um dos poucos médicos que fizeram parte dos bandos de cangaceiros foi Cícero Costa de Lacerda, paraibano, morto em 1923. Como o leitor pode imaginar, nessa cartografia, na falta de médicos ou de enfermeiras, os partos eram realizados em condições precárias de 
higiene e cuidados com a genitora e a criança. ${ }^{10}$ Assim, inúmeras infecções durante a gestação e vários tipos de complicações no parto poderiam pôr fim à vida da mãe e do bebê, tornando a mortalidade, nesses casos, nada desprezível:

Inúmeras afecções poderiam colocar em risco de vida a cangaceira grávida nos ermos da caatinga, sem médicos e assistência pré-natal: o abortamento e suas complicações, diabetes gestacional, trauma abdominal, hipertensão materna; além de descolamento prematuro da placenta, choque hemorrágico e apresentações anômalas ... Assim, das gestações de Maria Bonita, somente uma criança conseguiu sobreviver; justamente a que veio ao mundo pelas mãos de uma parteira (Almeida, 2006, p.116-117).

Pelo corpo do sujeito cangaceiro, outras subjetividades cortam o seu eu, despedaçam-no em muitos Lampiões, em múltiplas Marias Bonitas. Dadá relatou que, ao abraçar o ofício de cangaceira, levava consigo mezinhas, plantas, cachaça, álcool, água oxigenada, produtos com ação antibactericida que poderiam evitar o tétano (Araújo, Fernandes, 2005, p.93). De acordo com Oliveira (1982, p.134), lesões no abdome por arma de fogo ou arma branca eram fechadas com agulha de costurar couro. A retirada dos projéteis era feita sem anestesia: “Zé Sereno notou um 'caroço' no pescoço de Novo Tempo e perguntou: Que caroço é esse no seu pescoço, cumpadi? Será a bala do Ontoím dos pau preto? ... Nisso, botou a faca no fogo, derramou cachaça no gume, espremeu o 'caroço' entre o indicador e o polegar e deu pequeno talho: A bala pulou longe!" (Araújo, Fernandes, 2005, p.68).

Artes de fazer, artes de curar, artes de viver. Dadá procura, com o seu depoimento, elaborar uma escrita de si, vestígios de palavras e de histórias (Araújo, Fernandes, 2005, p.68). Em seu relato, procura detalhar como usava a água oxigenada para limpar as feridas, a cachaça para suportar as dores, as mezinhas para aliviar as perturbações. São mulheres como Dadá e Maria Bonita e homens como Lampião e Antonio Silvino que se reinventam como curadores, distanciando-se da identidade famigerada de matadores, violadores, estranguladores.

Palavras e histórias são igualmente evocadas por outros cangaceiros. Na escrita de Aglaê de Oliveira (1982), a farmacopeia dos bandos era formada por remédios feitos a partir do saber popular. Além disso, na cartografia do cangaço, era a circunstância que definia de que e como se alimentar, pois, como salienta a respeito Isnaia Firmina de Almeida (2006, p.119),

Quando perseguidos, se alimentavam às pressas, as colheres eram substituídas pelas mãos sujas em forma de concha, sem nenhuma higiene. Panelas de barro, latas e batatas de umbu eram utilizadas para cozinhar os alimentos, na maioria das vezes constituídos de carne seca de bode ou boi, rapadura e farinha. Quando nos "coitos" livres dos "macacos", os cangaceiros se alimentavam fartamente. Após as refeições descansavam, contavam os "causos" e gargalhavam.

A doença era tratada por múltiplos canais de recuperação. Uma gramática popular que inclui banha de ema para curar a asma, emplastro de clara de ovo batida com breu para cuidar de luxação e entorses, mastigar folhas de goiabeira branca para diminuir ou acabar com a halitose, suco de arnica para estancar as hemorragias, chá de pena de garça para os problemas de epilepsia, banhos de sândalo e alcaçuz para difteria etc. (Oliveira, 1982, p.131-139). 
Entre as doenças que assustavam os bandoleiros, estava o tétano, ferida que provoca febres, bala que rasga o corpo e expõe a dor. Feridos a bala, o melhor mesmo é aguardente, água oxigenada e pimenta malagueta seca. Deixe arder, deixe que a pimenta penetre na carne triada, raspada pelo metal perfurante da assassina bala. Permita que a cachaça seja absorvida pelos orifícios abertos pelo famigerado projétil, aquela maldita bala que foi disparada, talvez por um volante. Dói, dói muito sentir a pimenta e a cachaça ganharem os caminhos da carne machucada, conquistarem os espaços, brigarem pelos orifícios rasgados pelo inimigo. Analisando as práticas de cura entre os bandoleiros, Araújo e Fernandes (2005, p.92) afirmam que reza e grito eram ingredientes para suportar a dor provocada pela bala e pelo curativo. Muito mais grito do que reza! Gritos para fugir da dor, desse poder invisível que deflagrava a impotência humana diante da presença da morte.

Lampião, como todos os cangaceiros, tem o seu corpo escrito pela dor, pelos ferimentos. Há uma escrita que marca esse sujeito. ${ }^{11}$ Foi ferido a bala no ombro e na virilha, no município de Conceição do Piancó, Paraíba, em 1921; em 1922, o foi na cabeça; em 1924, no dorso e no pé direito, em Serra do Catolé, Pernambuco. Outros ferimentos também tatuaram seu corpo - em 1926, na omoplata; em 1930, no quadril. Mas para tais ferimentos havia remédios e recomendações, entre as quais evitar 'pisar em rastro de corno' ou, para evitar o tétano, vestir-se de preto e permanecer em um local escuro e incomunicável.

Outras gramáticas da sabedoria popular eram escritas e subjetivadas pelos homens do cangaço, a exemplo de Corisco. Para ele, o chá de quixabeira era um santo remédio para a cicatrização: "Andaram mais um pouco, e Corisco teve uma lipotímia (sensação de desmaio) decorrente da hemorragia dos seus ferimentos. Pararam. Dadá deu-lhe uma dose de cachaça de quixabeira, misturada com arnica e água de genuílo. Logo o ferido voltou a si, criou forças e retomaram a caminhada" (Araújo, Fernandes, 2005, p.30).

Nesse putativo 'espaço hospitalar', o cangaceiro aprendeu que lançar mão de tais práticas curativas significa ir sempre além de si mesmo. Trata-se de uma reescritura da vida quando se está a um passo do território da morte. Uma (re)escrita elaborada ao confeccionar seus artefatos, fazer os curativos, encanar pernas e braços quebrados e realizar partos das companheiras dos cangaceiros. ${ }^{12}$ Ao capturar esse saber popular, os cangaceiros constroem territórios discursivos, fabricam mecanismos que se autoalimentam da vontade que os criou. Tornam-se autores de curas, esculápios que escrevem um raio-X da vida, um diagnóstico para o corpo enfermo. Mesmo dispondo apenas da empiria e poucos procedimentos médicos, repassados principalmente por Cícero Costa, os bandoleiros conseguiam traçar prognósticos com relativo grau de acerto. É o que ocorria, por exemplo, nos casos em que a cor escura do sangue que saía do abdome baleado era interpretada como indicativo de um ferimento grave que, na maioria das vezes, trazia em si o signo da morte. ${ }^{13}$ De modo semelhante, a gravidade de um ferimento a bala no abdome era decidida por meio da prática de cheirar a ferida ${ }^{14}$, e se "os intestinos fossem perfurados, tratava-se de preparar a rede para enterrar: fedeu a cocô, fede a defunto" (Oliveira, 1982, p.134).

Para o corpo fraturado, luxado ou contundido, prescreviam-se cascas de jenipapo. Se a contusão ou traumatismo fosse ocasionado por coice de burro, receitava-se emplastro de mastruço, carvão moído e esterco de animal (Almeida, 2006, p.8), mistura que, caso não matasse o doente de infecção pelas impurezas do esterco animal, talvez pudesse curar! Por 
outro lado, juá e arnica eram recomendados para o tratamento de traumatismos decorrentes de quedas, acidentes, esmagamentos, 'peixeiradas' e tiros, entre outros:

Nessas horas de dor e proximidade da morte, mesmo sem dispor de registros precisos podemos idealizar que o discurso no cangaço se revestia de uma linguagem carregada de metáforas bélicas, com outros significados além dos manifestados explicitamente. Sob tais condições de medo e dor (em que até mesmo o corpo forjado na cartografia árida do cangaço sertanejo acabava por externar suas fraquezas), podemos supor o surgimento de significantes como 'matar a dor', 'fazer guerra contra o tétano', 'sitiar a morte', 'destruir o mau-olhado', 'fazer frente à mandinga', 'triturar o mal que assola o arraial'.

Nessa cartografia de saberes populares, valia quase tudo, desde as simpatias até o conhecimento farmacêutico, também repassado, às vezes, por Cícero Costa de Lacerda. Além disso, a prática de 'fechar o corpo' do sujeito cangaceiro contra os inimigos era uma constante. Amuletos e rezas eram táticas das quais se lançava mão para ter o 'corpo fechado', para livrar-se das picadas de animais peçonhentos: "Meizinhas (sic), amuletos e rezas eram utilizados para 'fechar o corpo' contra os inimigos ou para espantar cobras e animais peçonhentos, além de recomendações no mínimo estranhas: dessa forma, mulher menstruada era impedida de entrar nos quartos dos feridos de guerra, 'para não arruinar a ferida'" (Almeida, 2006, p.119-120).

Quando a reza e as simpatias não funcionavam, o jeito era apelar para outras práticas, como a tintura de iodo, a pomada de São Lázaro, para as chagas abertas no meio das brigas, e a banha de baiacu, para amenizar as dores de hérnias. O ex-cangaceiro e escritor Joaquim Góis argumentou que Lampião e seus 'cabras' traziam, como item dos 'primeiros socorros', uma "botica improvisada com tintura de iodo, pó de Joannes, água forte, pomada de São Lázaro, linha e agulha, algodão, um estojo de perfumes com brilhantina, óleo, extratos e essências baratas" (citado em Almeida, 2006, p.119).

Se uma serpente picasse alguma parte do corpo, somava-se à reza o ato de queimar imediatamente o local da picada, além de cortar com faca afiada a região atingida, para escorrer o veneno. Se o macho cangaceiro ou a fêmea bandoleira contraísse doenças venéreas, que se tratasse com o sumo de 12 limões, ingerido em jejum logo após o sol nascer. Era a mistura de uma crendice ácida com uma sabedoria limonada. O macho com tal doença que fechasse os olhos, pois a sabedoria popular recomendava que o mesmo não deveria olhar para mato verde nem para mulher - o que não era muito difícil, pois ambos eram muito escassos nessa geografia. Além disso, um ritual nada higiênico fazia parte desse cenário de dor e de pernas abertas: o homem tatuado pela marca da doença sexualmente transmitida deveria fugir dos banhos de rio porque, dizia a crendice, se o fizesse ficaria cego (Oliveira, 1982, p.132-135).

Nesse cenário os homens ordinários iam cartografando curas, montando ciladas para a doença. Quando a cefaleia atacava, recomendava-se folhas de algodão aquecidas ou, então, mascar gengibre. Se algum bandoleiro era acometido de faringite, o remédio era chá de formiga e gargarejo com sal. Para enterites, chá de cidreira. Para as cabeças cangaceiras com piolho, raspa de coco misturada com enxofre; porém, para funcionar direito, o 'cabra' não podia molhar a cabeça por oito dias. Devido às práticas às vezes nada higiênicas, muitos cangaceiros contraíam verminoses, e para isso a lavagem de manipueira era utilizada 
como purgante, que expelia os muitos organismos vivos instalados nas barrigas dos bandoleiros.

Nos anos iniciais do século XX, o cuidado com a impotência já fazia parte da escrita da masculinidade nordestina. Nesse caso, se o macho 'brochasse' e não correspondesse positivamente aos apelos sexuais da parceira, deveria tomar chá de velame, chá de cabeça de negro em jejum e água de arroz. Um conjunto de artifícios 'clínicos' para levantar os corpos caídos, desfalecidos, potentes ou impotentes (Oliveira, 1982, p.138).

São todas táticas de homens e de mulheres a mostrar que o cangaço tem outras histórias, outras memórias, outras escritas, outras linguagens, outras subjetividades. Receitas para corpos masculinos e femininos. Receitas para suspender a menstruação (semente de manjiroba em infusão; infusão de grão de café na aguardente por nove dias), receitas para fazer a febre alta estancar (suador de semente de melancia, casca de angico em água serenada), para as fragilidades do pulmão (leite de jumenta, ingerido pela manhã) e para as prisões de ventre (chá de raiz de gitirana retirada no nascente) (Almeida, 2006, p.121-122).

Táticas de viver para não morrer, vocabulário de vida para fugir da dor e da morte, linguagem de salvação para os quase perdidos, discursos de mestres e artesãos populares que tecem e bordam pedaços de vida, tricotam peles para si, tentando ressurgir a cada investida. Como as identidades do cangaço não têm um fim - são estilhaços que se partem em muitas direções, conforme o olhar do pesquisador -, como conclusão quero apenas parafrasear Jorge Larrosa (2003): o final desta escrita não é o final de sua história.

\section{NOTAS}

${ }^{1}$ Para Durval Muniz de Albuquerque Júnior (2001), o Nordeste só passou a existir como região a partir da segunda década do século XX. Neste artigo utilizo 'Nordeste' para melhor situar o leitor em relação à espacialidade, embora saiba que, no período em questão (final do século XIX e primeira década do século $\mathrm{XX}$ ), tal cartografia correspondia ao Norte do país.

${ }^{2}$ Sobre dobras e curvaturas, ver Domenèch, Tirado, Gómez, 2001.

${ }^{3}$ Apenas para lembrar Michel de Certeau (2002, p.34), deixo claro que toda leitura do passado, por mais controlada que seja pela análise documental, é dirigida por uma leitura do presente, um olhar que se lança de hoje para ontem.

${ }^{4}$ Sobre o conceito de cotidiano, ver Certeau, 1999. O cotidiano é compreendido como um conceito dialético, pois que, ao mesmo tempo em que traz uma noção de rotina, de repetição, também representa a criatividade, a criação.

${ }^{5}$ Conforme Certeau (1999, p.47), as táticas manifestam a que ponto a inteligência - entendida como a inventividade - é indissociável dos combates e prazeres cotidianos que articula, ao passo que as estratégias escondem, sob cálculos objetivos, sua relação com o poder que as sustenta, guardado pelo lugar próprio ou pela instituição.

${ }^{6}$ Neste artigo, dialogo com o conceito de identidade elaborado pelo sociólogo Stuart Hall, em particular na obra $A$ identidade cultural na pós-modernidade (2005).

${ }^{7}$ Para Hobsbawm e Ranger (2002), tradição inventada significa um conjunto de práticas de natureza ritual ou simbólica, que busca inculcar certos valores e normas de comportamentos por meio da repetição, o que, automaticamente, implica continuidade com um passado histórico adequado.

${ }^{8}$ Termo empregado pelos cangaceiros para designar os policiais que os perseguiam.

${ }^{9}$ Exibida pela TV Globo em 1982, a minissérie narrava o cotidiano dos cangaceiros nordestinos, com cenas gravadas nas trilhas por onde passou o bando coordenado por Lampião.

${ }^{10}$ Sobre este aspecto, assim se pronuncia Aglaê Lima de Oliveira (1982, p.137): "As bandidas tinham partos normais, sem nenhuma higiene. O umbigo do menino era cortado com unhas e não contraíam tétano". 
${ }^{11}$ Na edição de 5 de agosto de 1928 do jornal O Povo, de Fortaleza (Ceará), narra-se que os óculos de lentes escuras usados por Lampião serviam para esconder uma doença que atingira a córnea de seu olho direito.

${ }^{12}$ Sobre o tema, ver Vainsencher, s.d.

${ }^{13}$ Uma das explicações clínicas para esse fato é que a cor mais escura do sangue pode dever-se a uma lesão de uma veia calibrosa ou de um órgão maciço, o que pode ocasionar a morte do indivíduo ferido, em decorrência de perda substancial de sangue (Araújo, Fernandes, 2005, p.90).

${ }^{14}$ A esse respeito, afirma Isnaia Firmina Almeida (2006, p.117): “As lesões do intestino grosso, em virtude da flora e das características anatômicas e fisiológicas do órgão, são acompanhadas de índices consideráveis de mortalidade".

\section{REFERÊNCIAS}

ALBUQUERQUE JÚNIOR, Durval Muniz. Nos destinos de fronteira: história, espaço e identidade regional. Recife: Bagaço. 2008.

ALBUQUERQUE JÚNIOR, Durval Muniz de. História: a arte de inventar o passado. Bauru: EdUsc. 2007.

ALBUQUERQUE JÚNIOR, Durval Muniz de. O nordestino e a invenção do falo. Maceió: Catavento. 2004

ALBUQUERQUE JÚNIOR, Durval Muniz de. Zonas de encrenca: algumas reflexões sobre poder e espaços. Disponível em: http:// www.cchla.ufrn.br/ppgh/docentes/durval/ artigos/segunda_remessa/ zonas_de_encrenca.pdf. Acesso em: 26 set. 2008. [2001].

ALMEIDA, Isnaia Firmina.

Lampião: a medicina e o cangaço. Caos Revista Eletrônica de Ciências Sociais, João Pessoa, n.11, p.112-130. 2006. Disponível em: http://www.cchla.ufpb.br/caos/n11/09.pdf. Acesso em: 2 ago. 2011.

ARAÚJO, Antônio Amaury Corrêa de; FERNANDES, Leandro Cardoso de.

Lampião, a medicina e o cangaço. São Paulo: Traço. 2005

CERTEAU, Michel.

A escrita da história. Rio de Janeiro: Forense. 2002.

CERTEAU, Michel.

A invenção do cotidiano: artes de fazer. Rio de Janeiro: Vozes. 1999

DOMENÈCH, Miguel; TIRADO, Francisco; GÓMEZ, Lucía.

A dobra: psicologia e subjetivação. In: Silva, Tomaz Tadeu da (Ed.). Nunca fomos humanos: nos rastros do sujeito. Belo Horizonte: Autêntica. p.111-136. 2001.

HALL, Stuart.

A identidade cultural na pós-modernidade. Rio de Janeiro: DP\&A. 2005.

HOBSBAWN, Eric; RANGER, Terence.

A invenção das tradições. Rio de Janeiro: Paz e Terra. 2002.

LARROSA, Jorge.

Pedagogia profana. Belo Horizonte: Autêntica. 2003.

LE GOFF, Jacques (Org.).

As doenças têm histórias. Lisboa: Terramar. 1985.

LUCENA, Renata Valéria de; GOUVEIA

JÚNIOR, Mário.

Entre o rosário e o punhal: cangaço,

religiosidade e misticismo nos tempos de Lampião. Disponível em: http://

artigos.netsaber.com.br/resumo_artigo_5146/ artigo_sobre_entre_e_rosario_e_o_punhal:

_cangaco,_religiosidade_e_misticismo_ nos tempos de lampiao. Acesso em: 31 maio 2011. [2001].

MACHADO, Roberto.

A danação da norma. Rio de Janeiro: Graal. 1978.

OLIVEIRA, Aglaê.

Lampião, cangaço e Nordeste. Recife: O Cruzeiro. 1982.

QUEIROZ, Maria Isaura Pereira de.

História do cangaço: história popular. São Paulo: Global. 1991.

VAINSENCHER, Semira Adler.

Maria Bonita. Disponível em: http://

www.fundaj.gov.br. Acesso em: 4 set. 2007. s.d. 